\title{
CÔNG NGHỆ LIDAR TRONG THÀNH LẬP MÔ HİNH 3D KHU VỰC ĐÔ TH!
}

\author{
ThS. ĐẬNG THANH TÙNG ${ }^{(1)}$, ThS. HOÀNG THỦY(2), ThS. ĐINH TH! THU HIỀ ${ }^{(3)}$ \\ (1)Trường Đại học Tài nguyên và Môi trường Hà Nội \\ (2) Trường Đại học Mỏ địa chất, Đông Ngạc, Từ Liêm, Hà Nội \\ ${ }^{(3)}$ Viện Khoa học công nghệ Cơ khí, Tự động hóa và Môi trường
}

\section{Tóm tắt:}

Công nghệ Lidar hàng không thể hiện được nhiều ưu điểm trong công tác xây dựng mô hình 3D khu vực đô thị, việc nghiên cứu ứng dụng công nghệ Lidar để xây dựng bản đồ không gian ba chiều là rất cần thiết trong thời điểm hiện nay. Bài báo tóm lược phương pháp nghiên cứu và quá trình xử lý dữ liệu Lidar kết hợp với các dữ liệu đã có như ảnh hàng không, ảnh vệ tinh, bản đồ ... để xây dựng mô hình 3D khu vực đô thị tại thành phố Bắc Giang. Từ đó đưa ra một số đánh giá về khả năng, hiệu quả và tính khả thi của công nghệ Lidar áp dụng tại khu vực nghiên cứu.

\section{1. Đặt vấn đề}

Từ những năm 90 của thế kỷ 20 , công nghệ Lidar bắt đầu được sử dụng để phục vụ công tác nghiên cứu và khảo sát đặc điểm địa hình bề mặt trái đất. Có thể nói, đây là bước đột phá trong lĩnh vực đo đạc bản đồ.

Ở Việt Nam, một số đơn vị trực thuộc Bộ Tài nguyên và Môi trường như Tổng Công ty Tài nguyên và Môi trường, Trung tâm Viễn thám Quốc gia,... kết hợp với các đơn vị ở nước ngoài có thiết bị thu nhận dữ liệu Lidar đã tiến hành nghiên cứu ứng dụng thử nghiệm tại Cần thơ, Bắc Ninh, Bắc Giang, Nam Định, Thái Bình, Hưng Yên, Phủ Lý. Kết quả thử nghiệm tại Việt Nam cho thấy công nghệ Lidar có những tính năng vượt trội rõ rệt so với các công nghệ truyền thống, độ chính xác của các điểm độ cao của mô hình số địa hình có thể đạt tới $0,15 \mathrm{~m}$ đến $1 \mathrm{~m}$. Lidar có thể tạo được mô hình số địa hình với độ chính xác về độ cao rất tốt. Lidar có thể biểu diễn chi tiết địa hình bề mặt trái đất ở những khu vực có đặc điểm địa hình phức tạp, cây che phủ và dữ liệu Lidar có thể thu nhận được và không phụ thuộc vào thời gian (có thể thu nhận cả ngày và đêm) trong điều kiện thời tiết khắc nghiệt. Hệ thống Lidar sẽ phát huy hiệu quả cao khi thi công ở những vùng sâu, vùng xa, vùng khó khăn về giao thông, địa hình phức tạp và cần thời gian ngắn.

Bản đồ không gian ba chiều (3D) bao gồm nền mô hình số địa hình, các đối tượng địa hình và địa vật dạng vector được gắn kết với các thuộc tính và được hiển thị trong không gian ba chiều. Vì vậy, thông tin trên bản đồ $3 \mathrm{D}$ được đánh giá là giải pháp có ưu thế hơn hẳn so với bản đồ không gian hai chiều (2D) truyền thống. Để có được độ chính xác cao cho các đối tượng trên bản đồ thì nguồn dữ liệu thu nhận từ công tác bay quét Lidar được đánh giá là giải pháp tối ưu nhất.

Với những ưu thế và hiệu quả của việc xây dựng bản đồ không gian ba chiều phục vụ nhu cầu phát triển kinh tế -xã hội, đặc biệt là tốc độ phát triển đô thị ở Việt Nam đang rất nhanh thì việc nghiên cứu ứng dụng công nghệ Lidar để xây dựng bản đồ không gian ba chiều là rất cần thiết trong thời điểm hiện nay. 
2. Cơ sở phương pháp luâan và các ứng dụng của công nghệ Lidar Lidar

a) Khái niệm và bản chất của công nghệ

Công nghệ quét laser từ máy bay (Airborne Laser Scanning) hay còn gọi là Lidar (Light Detection And Ranging) là một công nghệ mới được áp dụng tại Việt Nam. Đây là công nghệ cho phép đo đạc độ cao chi tiết của địa hình một cách nhanh chóng và chính xác với mật độ các điểm dày đặc. Công nghệ Lidar thể hiện nhiều ưu thế vượt trội so với các công nghệ khác trong việc đo đạc thành lập bản đồ và xây dựng cơ sở dữ liệu cũng như công tác mô phỏng không gian ba chiều.

Hệ thống Lidar bao gồm bộ đầu quét (bộ cảm biến), hệ thống đo quán tính (IMU), hệ thống GPS, hệ thống quản lý bay, hệ thống camera số và hệ thống các thiết bị lưu trữ dữ liệu.

Hệ thống Lidar xác định được tọa độ các điểm trong không gian ba chiều $X, Y, Z$ ) bằng việc xác định độ $D$ dài của tia laser, xác định góc phương vị của tia quét (dựa vào các góc xoay của thiết bị và góc quay của gương quét được xác định bằng hệ thống IMU) và hệ tọa độ GPS lựa chọn tại thời điểm quét laser [2].

b) Cơ sở toán học và độ chính xác

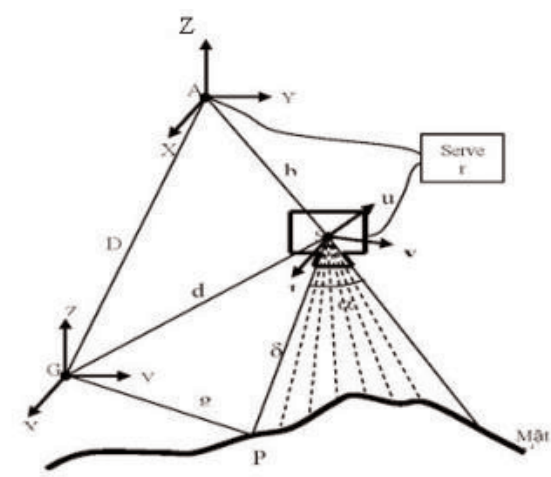

Hình 1: Cơ sở toán học xác định vị trí điểm Lidar.
Việc xác định tọa độ của các điểm Lidar được tiến hành bằng cách xác định tọa độ điểm Lidar trong hệ tọa độ của máy quét, sau đó xác định chính xác tọa độ của điểm Lidar trong một hệ tọa độ không gian lựa chọn. Do vậy cần thiết phải tính chuyển tọa độ từ hệ tọa độ đặt máy quét Lidar sang hệ tọa độ đã được lựa chọn. Sơ đồ vector sau minh họa việc xác định tọa độ của điểm Lidar như hình 1. Trong đó:

G: điểm GPS mặt đất trong hệ tọa độ lựa chọn.

A: Anntena của máy GPS trên máy bay.

S: điểm đặt máy quét Lidar.

$\mathrm{P}$ : điểm phạn xạ tia laser tại mặt đất. Với hai hệ tọa độ: hệ tọa độ được lựa chọn GXYZ; và hệ tọa độ đặt máy quét Lidar Suvt. Các dữ liệu quét bằng tia laser bao gồm: Dũ liệu mặt đất (các điểm nằm trên mặt đất); Dữ liệu các điểm không nằm trên mặt đất như các điểm nằm trên cây, mái nhà, dây điện; ... và dữ liệu ảnh cường độ phản xạ của tia laser cho phép nhận dạng địa vật một cách tương đối rõ nét.

Về độ chính xác xác định vị trí điểm Lidar chủ yếu phụ thuộc vào độ chính xác của hệ thống quét laser, độ chính xác xác định các thông số định hướng giữa hệ thống IMU và điểm đặt anntena trên máy bay, độ chính xác cơ sở trắc địa.

c) Khả năng ứng dụng của công nghệ Lidar và bản đồ $3 D$

- Ưng dụng trong công tác thành lập bản đồ địa hình

Hiện nay, bản đồ địa hình tỷ lệ lớn là một trong những sản phẩm được thành lập nhiều nhất dựa trên công nghệ Lidar. Công nghệ Lidar cho phép lập mô hình số địa hình có độ chính xác cao với thời gian nhanh chóng và ít phụ thuộc vào thời tiết, có thể bay quét Lidar cả ngày lẫn đêm. Hiện nay, công nghệ Lidar thường được áp dụng cho 
công tác thành lập bản đồ ở các tỷ lệ $1 / 1000,1 / 2000$ và $1 / 5000$.

- Ứng dụng trong công tác khảo sát, thiết kế, giám sát công trình

Dữ liệu Lidar có thể được thu nhận trong khoảng thời gian ngắn, có độ chính xác và độ chi tiết rất cao phục vụ công tác khảo sát, đặc biệt là khảo sát địa hình đạt hiệu quả cao. Kết quả của sản phẩm Lidar phục vụ khảo sát, thiết kế, giám sát công trình giúp cho việc tính toán khối lượng đào đắp, lên kế hoạch giải tỏa, đền bù sát với điều kiện thực tế hơn và bố trí các phương án, phương tiện thi công hiệu quả.

- Ứng dụng trong công tác thiết kế, quy hoạch, phát triển đô thị

Thiết kế - qui hoạch là một trong những lĩnh vực rất cần mô hình chi tiết. Từ thiết kế tuyến giao thông đô thị, hệ thống công trình công cộng đến thiết kế nhà máy thuỷ điện,... đều cần đến các thông tin chính xác về bề mặt địa hình để nghiên cứu tình trạng hiện thời, tính toán khối lượng đào đắp nhằm đưa ra phương án tối ưu, lên kế hoạch giải toả và tái định cư, hiển thị mô hình thiết kế, lấy ý kiến đóng góp, trình duyệt,... [7]

Ngoài ra, công nghệ Lidar còn được ứng dụng trong công tác phòng ngừa, đánh giá và giám sát thiên tai, và nhiều ứng dụng khác trong các lĩnh vực viễn thông, quân sự, du lịch, giáo dục và hàng không.

\section{Khái quát chung về khu vực thử nghiệm}

a) Đặc điểm chung

Khu vực TP. Bắc Giang nằm trong phạm vi: $\circ$

- Từ 21 15’37,5" đến 21 19'22,5" độ vĩ Bắc. $\circ$

- Từ 106 08'15" đến 106 13'44,5" độ kinh Đông.

Khu vực thử nghiệm nằm trong phạm vi mảnh bản đồ địa hình tỷ lệ $1 / 2.000$, có phiên hiệu mảnh là F-48-69-102-a. Tại khu vực này có địa hình đồi núi xen kẽ đồng bằng và các khu dân cư ven đồi, ven đường giao thông. Trong phạm vi khu vực thử nghiệm có khoảng 1500 nóc nhà.

Khu vực Bắc Giang đang được đầu tư xây dựng nhiều khu công nghiệp liên doanh với nước ngoài. Khu vực đô thị ngày càng được mở rộng và các khu dân cư ngoại thành đang phát triển theo hướng tập trung, đô thị hóa.

b) Các thông tin tư liệu trong khu vực thử nghiệm

Các thông tin tư liệu trong khu đo bao gồm:

- Điểm tọa độ Nhà nước hạng I: 10402 , 47 điểm địa chính cơ sở;

Tuyến độ cao hạng I bao gồm: I (LS-HN) $21,24,25,27,29,30,33$ và một số tuyến độ cao hạng III khác;

- Các tư liệu bản đồ địa hình: Bản đồ địa hình tỷ lệ $1 / 250.000$ theo lưới chiếu UTM in lại năm 1991; Bản đồ địa hình tỷ lệ 1/50.000 in lại năm 1978 gồm các mảnh: 6251I,II,III,IV, 6250-III; Bản đồ địa hình tỷ lệ 1/50.000 thành lập năm 2000. Bản đồ được số hoá, chuyển hệ và hiện chỉnh từ bản đồ tỷ lệ 1/50.000, gồm các mảnh: F-48-69$A, B, C$.

Các điểm tọa độ, độ cao nêu trên đảm bảo cho việc sử dụng làm điểm gốc để đo nối tọa độ, độ cao phục vụ bay quét Lidar. Dữ liệu bản đồ địa hình tỷ lệ $1 / 50.000$ khu đo được sử dụng làm tài liệu khi thiết kế [4].

c) Quy trình và hệ thống máy quét Lidar sử dụng trong khu vực (xem hinh 2)

- Lọc điểm phân loại dữ liệu Lidar thành các lớp bề mặt đất (ground) và không phải bề mặt đất (Non-ground).

- Tạo ảnh cường độ. 
- Xây dựng DEM sơ bộ.

- Nắn ảnh thẳng đứng (TrueOrtho) thành lập bình đồ trực ảnh trong hệ VN-2000.

- Chuẩn hóa dữ liệu DTM.

- Xây dựng DTM chính xác theo khuôn dạng phần mềm sử dụng.

- Chuyển đổi định dạng file, xây dựng DTM theo mô hình GRID.

- Xây dựng mô hình số bề mặt.

- Nhận dạng, xây dựng mô hình 3D nhà cửa.

- Kiểm tra nghiệm thu.

- Đóng gói, giao nộp sản phẩm.

\section{Phương pháp nghiên cứu}

a) Phương pháp Lidar

Giải pháp công nghệ quét laser đặt trên máy bay - Airborne Laser Scanning (ALS) hay còn gọi là LIDAR có thể thành lập DTM với độ chính xác rất cao từ $0,15 \mathrm{~m}-0,50 \mathrm{~m}$. Với khả năng thành lập cả mô hình số địa hình (DTM) lẫn mô hình số bề mặt (DSM) công nghệ LIDAR đặc biệt tỏ ra hữu ích khi được ứng dụng tại các vùng mà các phương pháp khác tỏ ra kém hiệu quả, chẳng hạn các vùng rừng, vùng cửa sông, đụn cát, vùng đất ngập nước hay quản lý vùng bờ và đặc biệt là có mức độ chi tiết cao để thực hiện xây dựng bản đồ 3D khu vực đô thị. Đặc biệt trong trường hợp cần xây dựng mô hình đô thị trong một thời gian ngắn bao gồm cả mô hình bề mặt mặt đất và cả mô hình nhà cửa với hình dạng chi tiết của mái nhà (roof shape).

Trong các ứng dụng dạng này, người ta thường kết hợp dữ liệu laser với các tài liệu khác trong quá trình thành lập bản đồ $3 D$ như: các dữ liệu GIS có săn về khối nhà, ảnh hàng không và vệ tinh để có thể đạt được kết quả tốt nhất.

b) Thành lập bản đồ địa hình 3D từ các nguồn ảnh viển thám khác

Ngoài ảnh máy bay thường dùng (ảnh quang học chụp từ các máy ảnh truyền thống dùng phim và gần đây là các máy ảnh số), ảnh viễn thám rất đa dạng, có thể phân loại thành hai nhóm chính là các loại ảnh vệ tinh và ảnh laser với đầu thu đặt trên máy bay. Thông thường, ảnh được sử dụng làm

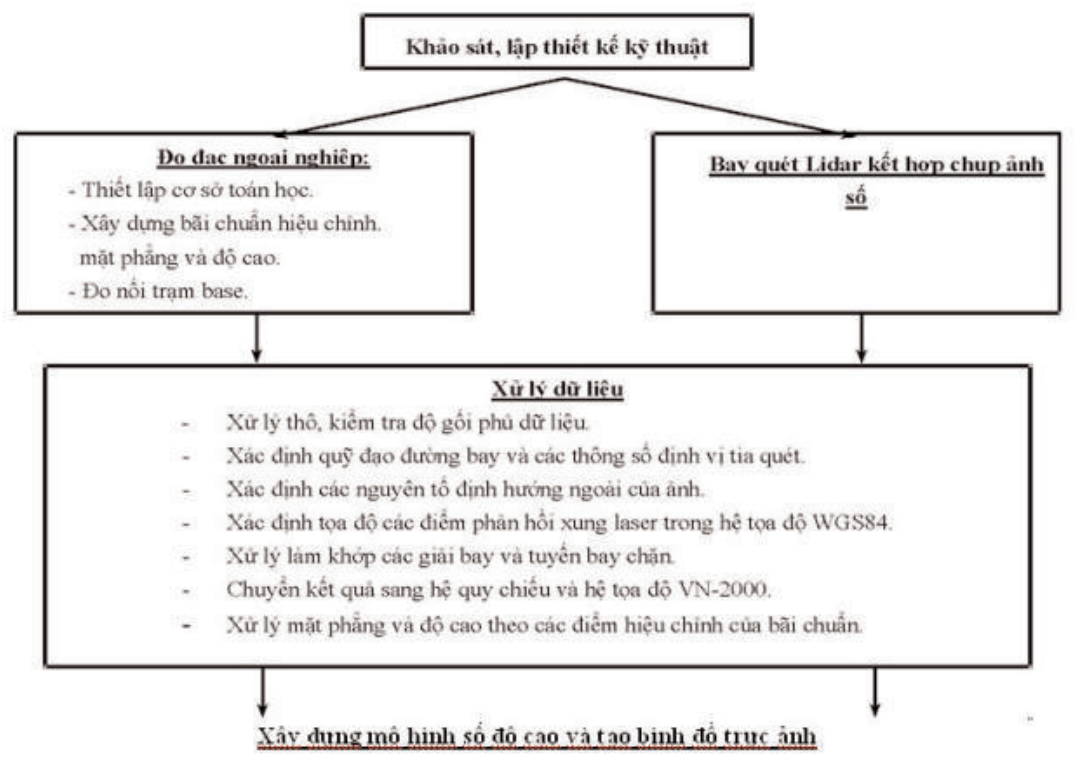

Hình 2: Quy trình công nghệ thành lập bản đồ 3D từ dữ liệu Lidar 
nền để số hóa các dữ liệu vector, các thông tin chi tiết về hình dạng và tính chất của các đối tượng nằm trên mặt địa hình, ảnh trực giao để phủ lên mô hình số địa hình tạo ảnh thực bề mặt mặt đất [1].

Độ phân giải của các loại ảnh viễn thám thay đổi từ vài $\mathrm{dm}$ đối với ảnh laser chụp từ máy bay đến trên dưới $1 \mathrm{~m}$ với các ảnh vệ tinh quang học panchromatic độ phân giải cao; các ảnh vệ tinh quang học đa phổ và ảnh Radar có độ phân giải kém hơn, từ vài mét đến vài trăm mét. Độ phân giải cũng như khả năng đo vẽ lập thể là các yếu tố quyết định các ảnh này có thể dùng để thành lập bản đồ tỷ lệ nào và sử dụng như thế nào.

Với sự đa dạng về đặc điểm cũng như khả năng ứng dụng của từng loại ảnh viễn thám cũng như tỷ lệ bản đồ $3 \mathrm{D}$ cần thành lập, khó có thể đưa ra một qui trình chính xác và chi tiết. Tuy nhiên qui trình thành lập này có rất nhiều điểm tương tự qui trình thành lập bản đồ 3D từ ảnh máy bay.

Trong nhiều trường hợp, ảnh viễn thám chỉ được sử dụng ở một công đoạn nhất định để thu thập một trong những nội dung cần thiết cho bản đồ $3 \mathrm{D}$ như dùng để tạo mô hình số địa hình và bổ trợ cho việc xác định ranh giới các địa vật. Ngoài ra, có thể kết hợp với khu vực có sã̃n mô hình số địa hình và dữ liệu vector thì ảnh vệ tinh quang học đa phổ có thể được nắn trực giao sử dụng mô hình số địa hình và dùng làm ảnh phủ bề mặt.

Đối với ảnh vệ tinh quang học độ phân giải cao như Ikonos, Quickbird hay Spot5, Spot6, VNRedSat độ phân giải trên dưới $1 \mathrm{~m}$, độ che phủ lớn và có thể đo vẽ lập thể thì qui trình thành lập bản đồ 3D tương tự như phương pháp dùng ảnh máy bay.

\section{Công tác bay quét và xử lý dữ liệu Lidar}

a) Một số chỉ số đối với công tác bay quét
Công tác bay quét phải đáp ứng đầy đủ các yêu cầu kỹ thuật đối với đo điểm trạm Base, đo bãi hiệu chỉnh mặt phẳng và độ cao, đo lưới khống chế cơ sở, đo chi tiết bãi hiệu chỉnh mặt phẳng và độ cao cùng các thông số và quy định khác dành cho công tác bay chụp.

Để đảm bảo độ chính xác yêu cầu trong công tác bay quét LiDAR, mỗi khu bay chụp phải có các bãi hiệu chỉnh mặt phẳng và độ cao. Bãi hiệu chỉnh cho các khu bay ở Bắc Giang được thiết kế như sau với 3 bãi hiệu chỉnh, trong đó: 2 bãi hiệu chỉnh cả mặt phẳng và độ cao, bãi thứ 3 chỉ hiệu chỉnh về mặt phẳng.

Khu bay Bắc Giang thiết kế 6 điểm khống chế: GPS48; GPS49; GPS50; GPS51; GPS56; GPS57. Riêng đối với 2 điểm GPS48, GPS49 thiết kế phục vụ hiệu chỉnh mặt phẳng nên không tiến hành đo nối độ cao hạng IV.

Tại mỗi bãi hiệu chỉnh xác định tọa độ, độ cao tối thiểu 50 điểm hiệu chỉnh mặt phẳng và độ cao trên mặt đất và tối thiểu 5 đồ hình địa vật sắc nét có sự tương phản khác biệt lớn với các địa vật xung quanh như nhà, sân, bãi cỏ. Có khoảng 150 điểm được lựa chọn cho khu Bắc Giang.

Khu bay Bắc Giang có diện tích bay chụp khoảng: $135 \mathrm{~km}^{2}$ với 29 đường bay (trong đó có 22 đường bay chính và 7 đường bay bổ sung), tổng chiều dài bay khoảng $300 \mathrm{~km}$, tổng số giờ bay khoảng 8,5 giờ. (Xem hình 3)

\section{b) Xử lý dũr liệu Lidar}

Quy trình xử lý dữ liệu Lidar bao gồm có xử lý dữ liệu thô, kiểm tra độ phủ của dữ liệu; Xử lý số liệu GPS/IMU; Xử lý nguyên tố định hướng ngoài (EO); Xử lý dữ liệu Laser, tạo DSM/DTM/ảnh cường độ xám. Việc xử lý dữ liệu Lidar yêu cầu tuân thủ đúng theo các quy định kỹ thuật xử lý dữ liệu. 


\section{Xây dựng mô hình 3D khu vực thử nghiệm}

a) Tạo mô hình số địa hình, bề mặt

Dữ liệu Lidar thu nhận được của khu vực thử nghiệm sau khi xử lý kết hợp với chia tách các tầng độ cao của mảnh bản đồ $\mathrm{F}$ 48-69-102a tại khu vực thành phố Bắc Giang, chúng ta thu nhận được dữ liệu mô hình số bề mặt và mô hình số địa hình cùng với nhà cửa, các công trình xây dựng. Ở đây, dữ liệu mô hình số bề mặt bao gồm 1.345.195 điểm tọa độ, độ cao của tầng dữ liệu phản hồi đầu tiên (first-echo); dữ liệu tầng phản hồi sau cùng có 1.343 .493 điểm (last-echo), trong đó sẽ bao gồm các điểm nằm trên bề mặt thực địa và các điểm nằm trên bề mặt các đối tượng cứng như nhà cửa, công trình xây dựng (không bao gồm các dữ liệu điểm nằm trên bề mặt cây cối...). Sau đó sử dụng module 3D Analyst của hệ thống phần mềm ArcGIS để xây dựng mô hình số địa hình và mô hình số bề mặt. Công việc này được tiến hành bằng công cụ Creat TIN from feature nhằm lấy giá trị tọa độ và độ cao của tập hợp các điểm Lidar thu nhận được để nội suy ra mô hình số bề mặt và mô hình số địa hình. (Xem hinh 4)

\section{b) Nắn ảnh trực giao}

Ảnh hàng không được thu nhận cùng quá trình bay quét Lidar được tiến hành nắn trực giao (trueorthophoto) để hỗ trợ công tác nhận dạng, phânn tích đoán đọc các đối tượng trên khu vực được thuân lợi hơn phục vụ công tác thành lập mô hình, bản đồ 3D. Để nắn ảnh trực giao cho khu vực nghiên cứu, số liệu đầu vào cần có là: Mô hình số bề mặt DSM (độ phân phân giải 0.5 $\mathrm{m})$, thông số định hướng ngoài của các tấm ảnh (EO), ảnh đã phát triển. Kết quả cho ảnh nắn khuôn dạng của TOPPIT. Độ phân giải của ảnh nắn tối đa bằng $1 / 2$ độ phân

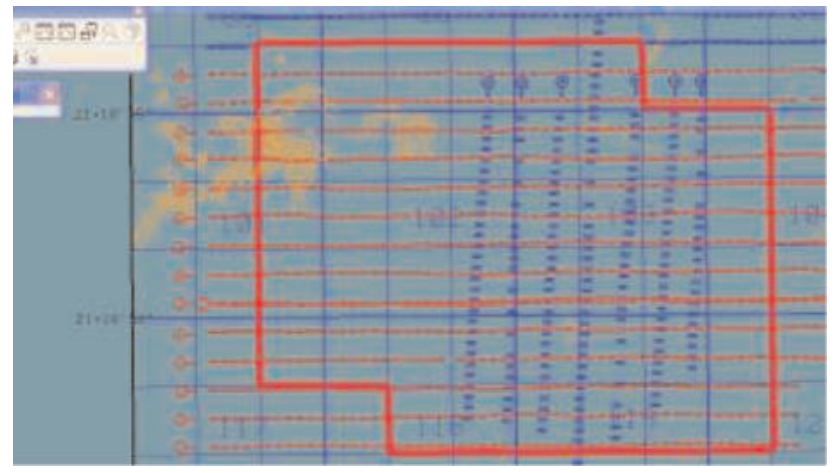

Hình 3: Sơ đồ tuyến bay quét Lidar khu vực thành phố Bắc Giang
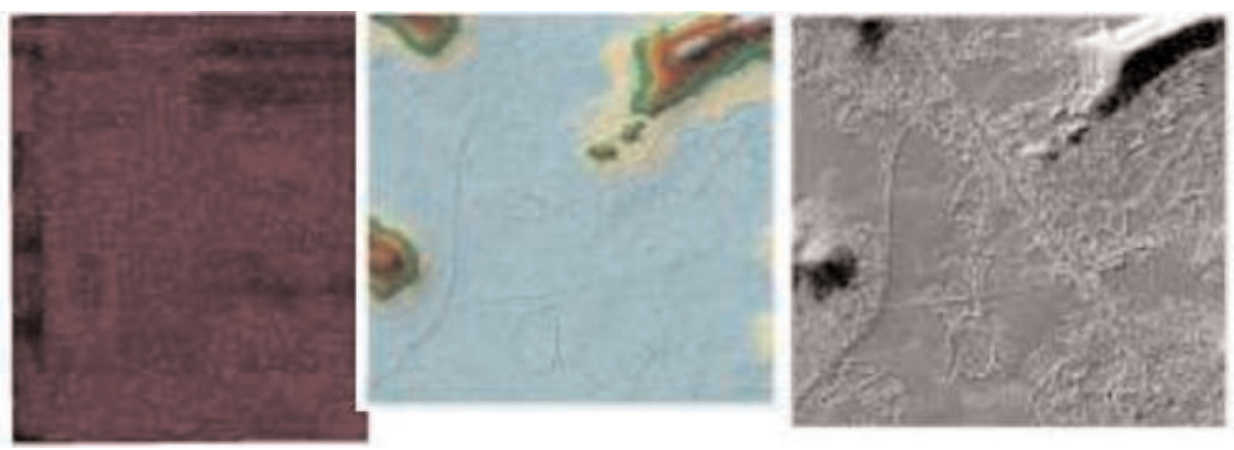

Hình 4: Dữ liệu các tầng phản hồi và mô hình số 
giải của DSM (trong công trình này Pixel size $=0.25 \mathrm{~m}$ ). Sau đó lần lượt ghép các ảnh trong từng dải với nhau, ghép các dải trong khu đo với nhau để tạo thành một ảnh của cả khu bay (project). Bước cuối cùng là chương trình sẽ cắt ảnh ghép cả khu vực theo từng mảnh bản đồ và chuyển đổi sang dạng tif.

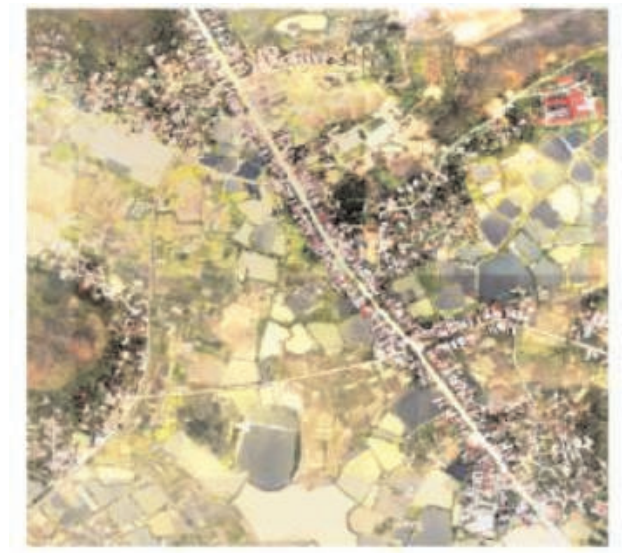

Hình 5: Ảnh trực giao

c) Phủ ảnh trực giao trên nền mô hình số địa hình

Ảnh được phủ lên trên nền mô hình số địa hình để tạo ra những nhận biết rất thực về khu vực. Để hiển thị được các ảnh này trong mô hình lập thể của ArcScene chúng cần phải được nắn chỉnh về cùng hệ tọa độ với các nội đúng vector của bản đồ địa hình 3D.

Ảnh trực giao khi phủ lên DTM làm nền cho người quan sát cảm giác địa hình khá ấn tượng nhất là khi chuyển động trong không gian ở độ cao tương đối lớn (xem hìn 6)

d) Xây dựng các đối tượng nhà cửa, công trình xây dụ̂ng trên nền địa hình $3 D$.

Trên bản đồ địa hình 3D, nhà có thể được thể hiện bằng các polygon đường viền chân nhà gắn thuộc tính độ cao nhà, độ chịu lửa. Độ cao này được thu thập từ kết quả của dữ liệu Lidar phản hồi cuối cùng (last-echo) như đã nêu ở trên. Đầu tiên, lớp polygon nhà được phủ lên mặt DTM bằng công cụ Baseheight.

Sau đó, các khối nhà được dựng lên bằng công cụ Extrusion sử dụng độ cao nhà đã được xây dựng từ dữ liệu last-echo. Chọn smooth shading và hide backside cho việc chiếu sáng và tạo bóng của các khối nhà. Trong trường hợp này các chi tiết về hình dáng mái và các tầng trên đều được khái quát hóa.

Tuy nhiên, có thể chọn lọc một số khối nhà quan trọng có tính định hướng cao để thể hiện chi tiết hơn giữa các nhà bình thường được hiển thị theo nguyên tắc đơn giản nói trên. Với công cụ 3D building có thể dựng khối nhà lên từ footprint và gán hình ảnh thật của các bề mặt nhà lên đó. (Xem hinh 7)

Để thực hiện việc thể hiện chi tiết khối nhà, trước hết cần chuẩn bị ảnh *.BMP của các bềmặt nhà và mái nhà. Các dữ liệu ảnh trên được lấy từ ảnh hàng không trực giao và ảnh chụp tại thực địa. Có thể lặp lại việc gán ảnh bề mặt nhiều lần cho các nhóm nhà có hình ảnh bề mặt khác nhau. Kết quả có

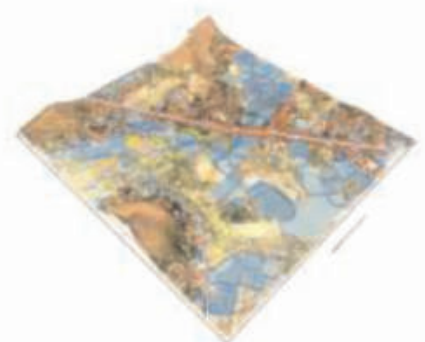

Hình 6: Bản đồ và ảnh trực giao phủ trên mô hình số địa hình 

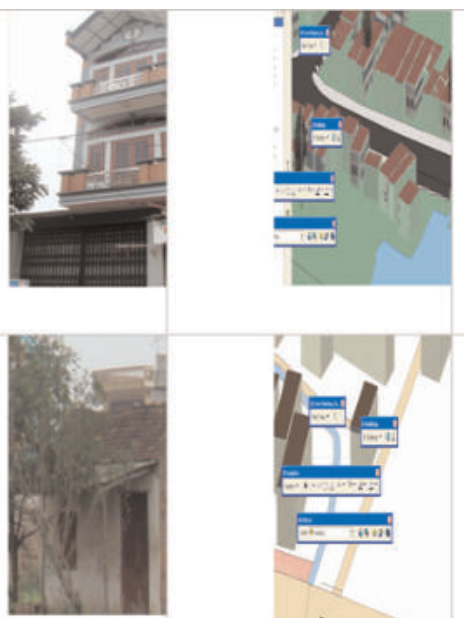

a. Hình ảnh ngoài thực địa

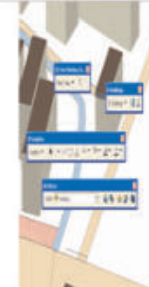

b. Hình ảnh

$3 D$ khái quát hóa
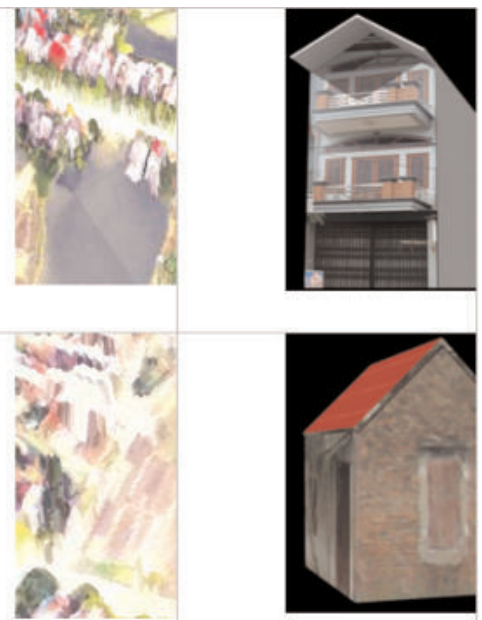

c. Hinh ảnh $3 D$ khi phủ ảnh hàng không lên

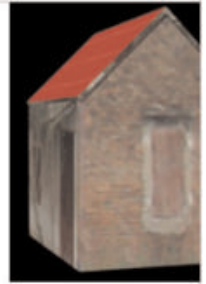

d. Hinh ảnh 3D chi tiết DSM

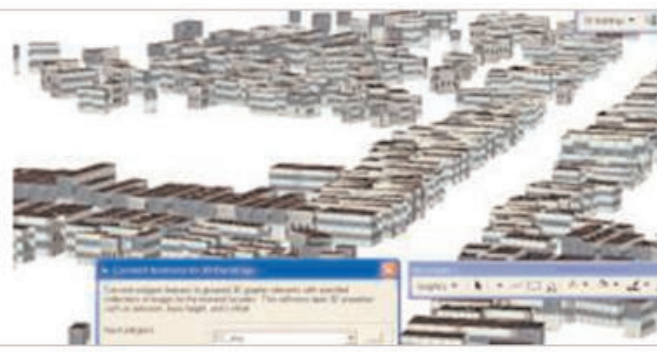

Hình 7: Các khối nhà được thể hiện bằng công nghệ 3D building thể cùng được lưu trữ dưới dạng *.LYR là dạng dữ liệu mặc định của ArcScene. Cách thể hiện này đặc biệt phù hợp với các nhà cao tầng của các khu đô thị [9]. đồ

e) Thể hiện các đối tượng khác trên bản

Ngoài ra, các đối tượng khác được phủ lên mặt DTM cũng cần thiết phải tuân thủ quy định ký hiệu và màu riêng, bao gồm có:

-Thuỷ hệ và các đối tượng liên quan: Sông hai nét, sông một nét được phủ lên mặt DTM bằng công cụ Baseheight. Sông suối chảy theo mùa được thể hiện bằng hai ký hiệu khác nhau.

+ Đê điều: các chi tiết về độ chênh cao của đê được bổ sung vào DTM dựa trên các số liệu có được về đê như vị trí mặt đê, vị trí chân đê, độ cao mặt đê, tỷ cao đê.

+ Cống được thể hiện bằng đoạn thẳng đặt vuông góc với kênh mương bằng màu đen. Các thông tin về tên kênh mương, tên cống, thiết bị điều tiết nước nếu có được gắn vào bảng thuộc tính của cống.

- Giao thông và các đối tượng liên quan: đường ô tô được thể hiện phần trải mặt đường bằng ảnh thực của loại chất liệu, trục phân tuyến, vỉa hè và được gắn các thuộc tính về tên đường, chất liệu rải mặt, độ rộng đường, độ rộng phần trải mặt,.v.v...; đường đất nhỏ và đường mòn;

Các đối tượng dạng điểm liên quan như trạm ghi, cột đèn hiệu, cột tín hiệu, cột cây 
số, biển chỉ đường nếu có cũng được dựng lên bằng công cụ Plan tree trên mặt DTM [1].

- Các đối tượng kinh tế, văn hoá xã hội

Trên bản đồ 3D, ở mức độ chi tiết rất cao có thể thể hiện các đối tượng kinh tế, văn hóa xã hội bằng mô hình $3 \mathrm{D}$ thực của đối tượng được chuẩn bị sẵn trong môi trường đồ họa. Ở mức độ chi tiết thấp hơn, các đối tượng văn hóa, kinh tế, xã hội có thể được thể hiện bằng công cụ Plant tree sử dụng ảnh lấy từ các ký hiệu mẫu của bản đồ địa hình 2D.

- Đường dây điện và đường dây thông tin được thể hiện độc lập bằng hai loại đối tượng: đối tượng dạng điểm thể hiện cột, được gắn các thông tin thuộc tính về chiều cao cột, cột cao thế hay hạ thế được điều tra từ thực địa; Đường dây tải điện đối tượng dạng đường đơn giản được gắn thuộc tính về loại đường: cao thế, hạ thế; độ cao trung bình của đường dây; điện áp nếu có.

Một đối tượng có nhiều điểm tương tự với các loại dây dẫn là ống dẫn. Ống dẫn được thể hiện là dạng đường, màu xám sẫm, gắn các thuộc tính: tỷ cao, đường kính ống, vật liệu làm ống, chất dẫn trong ống.

\section{- Dáng đất, chất đất}

Dáng đất đã được thể hiện bằng mô hình số độ cao DTM và đường bình độ. Còn các thông tin về chất đất được thể hiện bằng các đối tượng dạng vùng phủ lên mặt.

- Thực vật

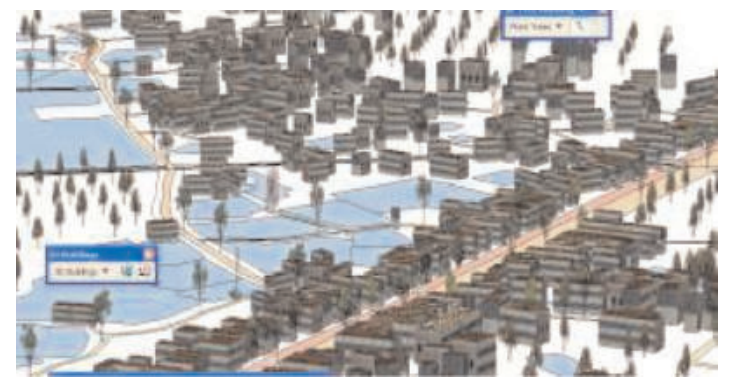

Các đối tượng thực vật có độ cao riêng thấp như cỏ, lúa, hoa màu... sẽ được thể hiện là đối tượng dạng vùng phủ lên mặt DTM. Ở tỷ lệ lớn, các đối tượng thực vật có độ cao riêng lớn như rừng, hàng cây, cây độc lập có thể được thể hiện bằng các đối tượng dạng điểm. (Xem hình 8)

- Ranh gióri

Ranh giới hành chính các cấp, ranh giới khu cấm, ranh giới sử dụng đất được thể hiện ngay trên mặt DTM bằng hai ký hiệu. Một ký hiệu được tạo ra từ linestyle phục vụ mục đích hiển thị. Ký hiệu thứ hai được thể hiện bằng đường đơn giản chạy liên tục, gắn các thuộc tính về loại ranh giới, tên của các đơn vị hành chính các cấp nằm hai bên, tên của khu vực cấm để phục vụ cho mục đích truy vấn thông tin.

Các đơn vị hành chính thì được thể hiện ở dạng vùng bằng các Polygon được gắn các thuộc tính như mã hành chính, tên riêng và một số số liệu thống kê quan trọng của đơn vị hành chính.

- Ghi chú

Một số ghi chú dạng số được sử dụng để xác định kích thước hay vị trí hình học của đối tượng. Các thuộc tính này đều có thể được truy cập bằng các công cụ query hay info của ArcScene. Hơn nữa các đối tượng địa hình khi được dựng lên trong môi trường lập thể khá dày đặc nên chỉ một số ghi chú quan trọng được chọn để thể hiện trong Scene của ArcScene [1].

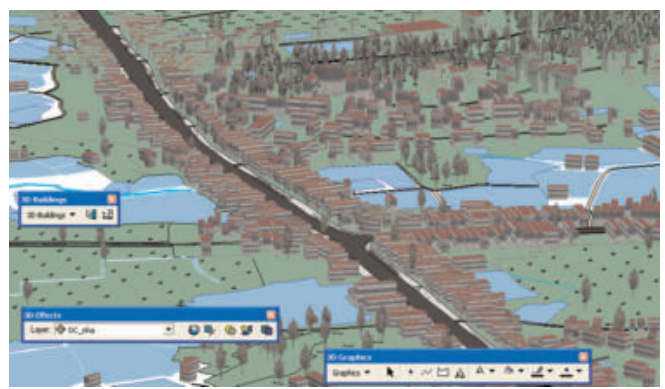

Hình 8: Hình ảnh cây cối thể hiện bằng công nghệ 3D plant tree 


\section{Kết luận và đề xuất}

Công nghệ Lidar phục vụ cho công tác lập mô hình số địa hình (DTM) và bản đồ không gian (3D) độ chính xác cao là một bước đột phá trong việc ứng dụng công nghệ và kỹ thuật tiên tiến để tạo lập các sản phẩm có chất lượng và độ chính xác cao đáp ứng các yêu cầu và nhiệm vụ phát triển kinh tế bảo vệ an ninh quốc phòng trong giai đoạn hiện nay.

Ứng dụng công nghệ Lidar lập bản đồ không gian 3D mang lại hiệu quả kinh tế cao, đảm bảo độ chính xác và nâng cao năng suất lao động, nâng cao chất lượng sản phẩm.

Hệ thống công nghệ quét Laser mặt đất Lidar là thiết bị đặc biệt chuyên ngành chỉ có một vài nhà sản xuất trên thế giới cung cấp. Do đó khi thực hiện cần dựa trên tình hình thực tế để áp dụng các hệ thống Lidar sao cho phù hợp với yêu cầu, mục đích.

Công nghệ LIDAR cũng tỏ ra ưu việt hơn các công nghệ khác trong lập bản đồ $3 D$ khu vực đô thị, đặc biệt trong trường hợp cần xây dựng mô hình đô thị trong một thời gian ngắn bao gồm cả mô hình bề mặt mặt đất và cả mô hình nhà cửa với hình dạng chi tiết. Trong các ứng dụng dạng này, người ta thường kết hợp dữ liệu lidar với các tài liệu khác trong quá trình thành lập bản đồ $3 D$ như: các dữ liệu GIS có sẵn về khối nhà, các ảnh hàng không và vệ tinh để có thể đạt được kết quả tốt nhất.

Bản đồ $3 D$ được thành lập từ dữ liệu Lidar đem lại hiệu quả cao về nhiều mặt và đạt chất lượng tốt. Đề nghị nghiên cứu, ứng dụng rộng rãi hơn nữa tại Việt Nam.O

\section{Tài liệu tham khảo}

[1]. Nguyễn Thị Thục Anh. Nghiên cứu thử nghiệm thành lập bản đồ địa hình 3D. Trung tâm Viễn thám quốc gia, Bộ Tài Ngày nhận bài: 15/8/2014. nguyên và Môi trường. Hà Nội, 2012.

[2]. Lương Chính Kế. Thành lập DTM bằng công nghệ Lidar. Tạp chí Viễn thám và địa tin học, Tr.20-27. Hà Nội, 2009.

[3]. Phan Văn Lộc. Tự động hóa đo ảnh. Bài giảng cho NCS và $\mathrm{HVCH}$. Đại học Mỏ Địa chất. Hà Nội, 2007.

[4]. Công ty Đo đạc ảnh địa hình. Báo cáo kết quả tích hợp hệ thống máy ảnh số và Lidar Harrier 56 tại Việt Nam. Hà Nội, 2010.

[5]. Liang Chen Chen, Tee-Ann Teo, Jiann-Yeo Rau, Jin-King Liu, Wei-Chen Hsu. Buiding reconstruction from Lidar data and Aerial Imagery. Taiwaan, 2006.

[6]. R.O.C. Tse, M. Dakowicz, C.M. Gold, and D,B. Kidner. Building reconstruction using Lidar data. GIS Reseach Center, School of Computing, University of Glamorgan, Pontyrpidd, CF37 IDL, Wales, UK, 2008.

[7]. G. Prisestnall, J. Jaafar, and A. Duncan, 2009. Extraction of Urban Features from Lidar Digital Surface Models, Computers, Environment \$ Urban Systems, Vol. 24, pp.65-78.

[8]. Rottensteiner, F, Trinder, J., Clode, S. and Kubik, K. Fusing Airborne Laser Scanner Data and Aerial Imagery for the Automatic Extraction of Buildings in Densely Built-up Areas, Proceedings of XXth Congress of ISPRS, Istanbul, Turkey, 12-23 July, 2010, pp. 512517

[9]. Fritsch, D, 2009. 3D Building Visualisation Outdoor and Indoor Applications, Photogrammetric Week '03, pp. 281-290 Proceedings, 4th Intemational Symposium on Spatial Data handling, Zỹrich, Vol 2, pp. 830-843.

[10]. Molenaar, M, 2010. A Formal Data Structure for Three Dimensional Vector Maps. $O$ 